\title{
Multiple-Projectile Penetrating Neck Injury from a Modified Nail-Containing Gas Pistol
}

\author{
Dimitar Dimitrov Pazardzhikliev
}

Department of Otorhinolaryngology, University Hospital “St. George”, Plovdiv, Bulgaria

Background: Penetrating neck injuries result from missiles and stab wounds. A gas pistol is a non-lethal weapon for selfdefence.

Case Report: We present a case where the use of a modified gun led to multiple injuries in a single shot. Four projectiles were embedded in the neck, one in the larynx and three in the cervical spine. The first was removed via a combined external and endoscopic approach, while the rest were put on follow-up.

Conclusion: The reported case shows that damage from modified gas pistols, although rarely life threatening, may cause long term discomfort and diminished quality of life. (Balkan Med J 2014;31:254-6).

Key Words: Gas pistol, neck injury, penetrating
Penetrating neck injuries result from missiles and pointed objects. Thirty percent of penetrating injuries involve multiple structures. They may be either mild or life threatening with early and late stage complications. However, $80 \%$ may be managed conservatively (1). In $25 \%$, large vessels are involved, the aerodigestive tract and neural structures in 10\% (2-5).

\section{CASE PRESENTATION}

A gas pistol is a non-lethal weapon for self-defence, but can be modified to cause such damage. This is the case in the following report, for which we have obtained an informed consent from the patient.

A male 43 years of age had been shot from close distance in the neck with a single shot from a gas pistol. Immediate pain in his right shoulder, throat, and cough followed. He was transported to the emergency department in supine position, without neck immobilisation. His breathing rate and saturation were normal, there was no breathing compromise in terms of stridor or increased breathing effort. He had several pin-sized wounds in the neck and a massive subcutaneous emphysema, but no bleeding, and pneumothorax. He had no airway compromise, no digestive tract perforation or tracheoesophageal fistula.

Computed tomography (CT) reported massive subcutaneous emphysema and pneumomediastinum and a radio opaque foreign body in the cricoid on the right side (Figure 1). However, on the scout image 4 foreign bodies were witnessed. Three other foreign bodies were overlooked. One was obliquely settled between cervical vertebrae 4 and 5 starting from the vertebral artery foramen, passing though the intervertebral foramen and ending in the spinal canal on the right (Figure 2-4), one in the intervertebral foramen between thoracic vertebrae 1 and 2 on the right and one in the body of thoracic vertebra 1 (Figure 5). There was no neurological deficit except for shoulder pain and numbness of the forearm.

The patient was put on antibiotics and an elective tracheostomy was performed to allow manipulation of the airway without risk of further complications. Endoscopic extraction proved impossible and we converted to an open approach via an apron neck incision. The foreign body was found in the area of the oblique part of the right cricothyroid muscle. On attempting to grasp it with a haemostat it migrated into the airway. We managed to extract the foreign body endoscopically and tracheotomy proved useful.

Electromyography revealed severely diminished axonal conduction for the axillary nerve. The neurosurgeons' opinion was that removal of the remaining projectiles exceeded the risk of complications and the patient was left on follow-up. Currently, two years after the accident, the patient is without any complaints except for intermittent pain in the right shoulder and numbness on the lateral aspect of his right forearm. On control CTs there are no signs of migration of the vertebral foreign bodies. 


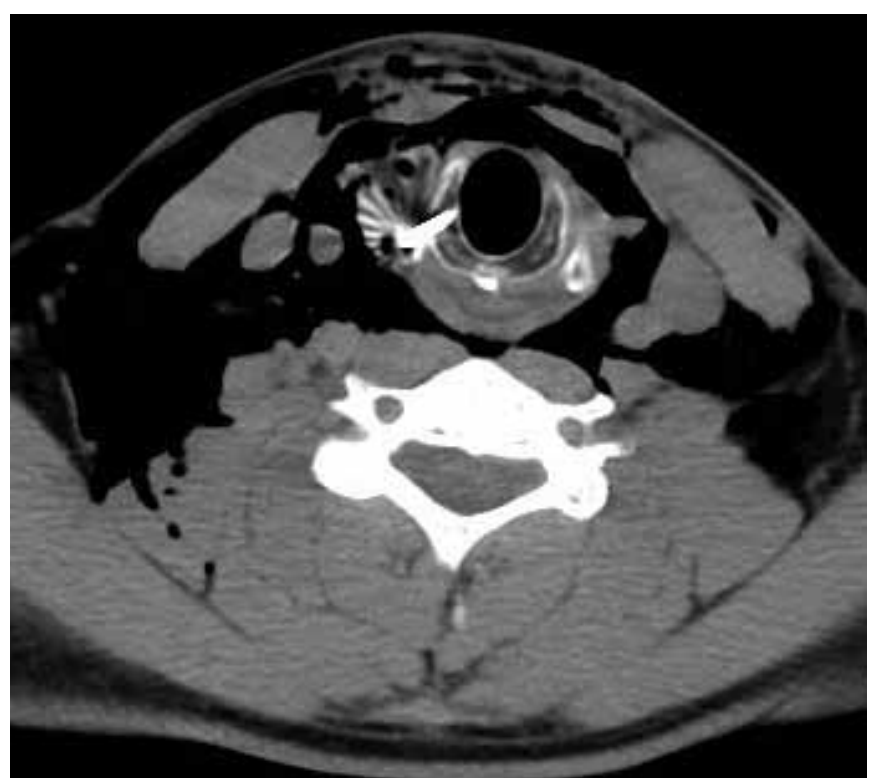

FIG. 1. The cricoid on the right side

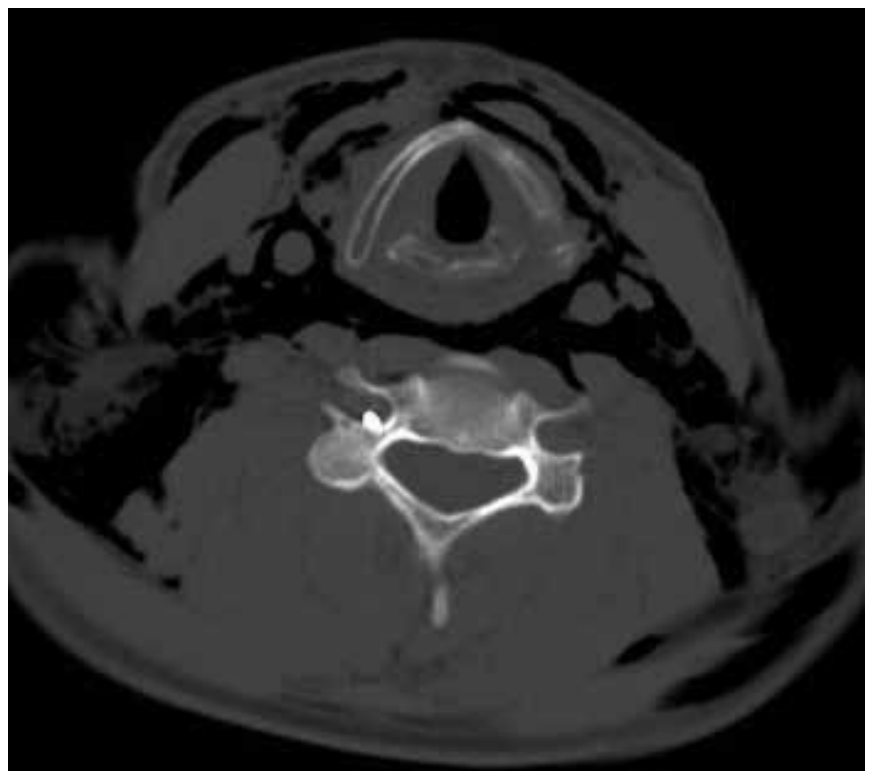

FIG. 2. Projectile settled between cervical vertebrae 4-5 starting from vertebral artery foramen

The foreign body removed proved to be a nail with a clipped head. The pistol used was a $9 \mathrm{~mm}$ EKOL Dicle (Voltran Av Silahları Industry and Trade Limited Company). Bulgarian legislation considers such gas pistols to be non-lethal weapons and they can be freely accessed at the market, but a registry is kept both at the store and by the police. However, in this case the ammunition used had been modified. It had been opened, stuffed with clipped head nails and sealed again with wax.

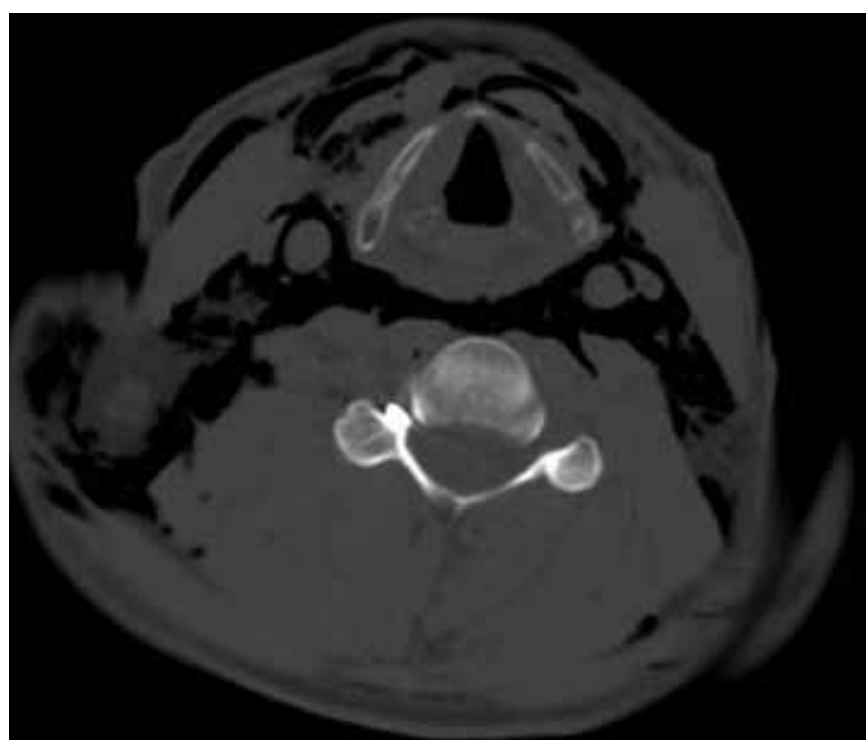

FIG. 3. Projectile settled between cervical vertebrae 4-5 passing though intervertebral foramen

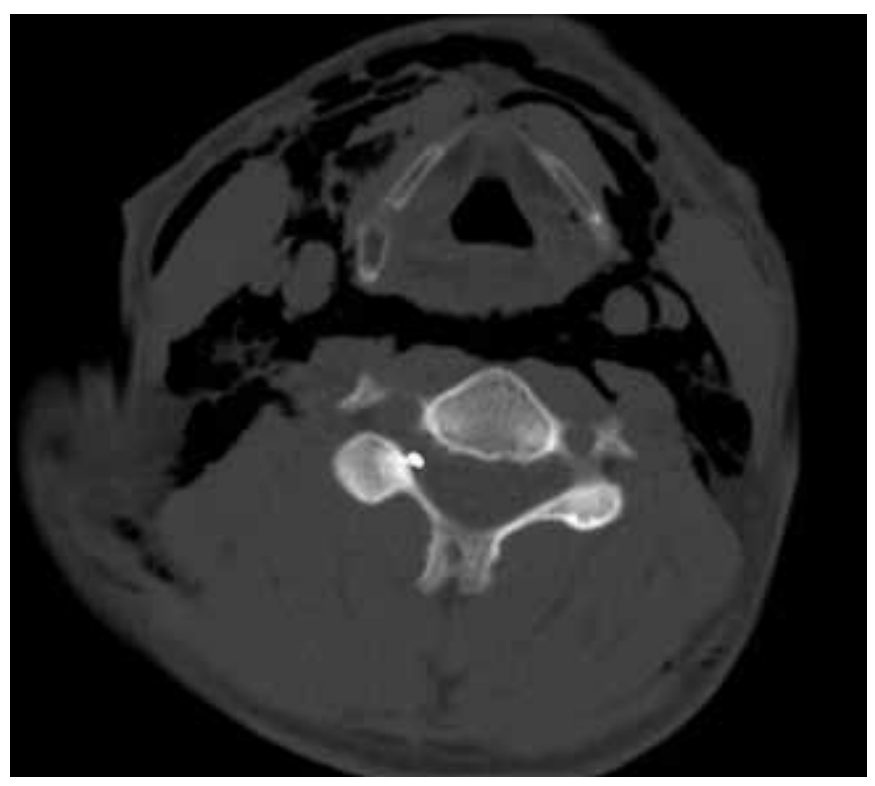

FIG. 4. Projectile settled between cervical vertebrae $4-5$ ending in the spinal canal on the right

\section{DISCUSSION}

In this case, luckily, neither major vessels nor the digestive tract were involved. Injuries were to the upper airway, spine and nerve roots in Zone II and III and the patient was haemodynamically stable. Up to $80 \%$ of such cases may be treated conservatively (1). A foreign body in a region of the upper airway prone to posttraumatic stenosis warranted an active attitude in this case. It was eventually removed using a combined approach. 


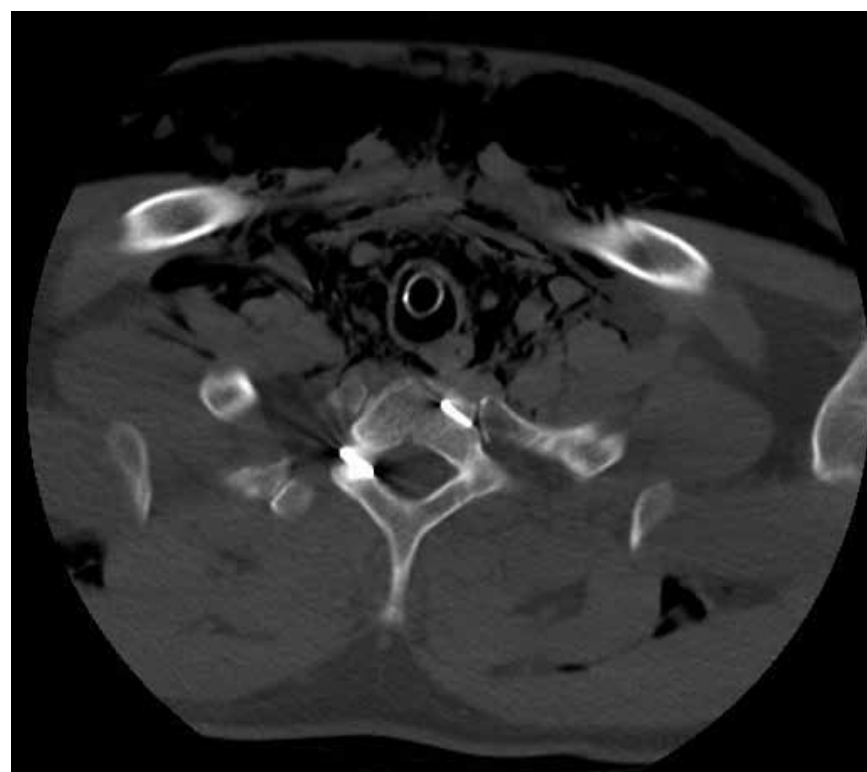

FIG. 5. Projectile in intervertebral foramen of thoracic vertebrae 1-2 on the right, and in the body of thoracic vertebra 1

Penetrating neck injuries from nail guns have been published previously, including multiple ones $(6,7)$. However, we did not find in publications in the literature of injuries from modified gas pistols. What is different in this case is that the nails had their heads clippedoff. The purpose seems to be to stuff a few of them in a single bullet and increase the possibility of damage. Their size was the reason why they embedded near totally in bone and cartilage. Consequently, they might, first, be overlooked and, second, extraction might be troublesome, in contrast to other cases of nail gun injuries. The foreign bodies abutted important structures - the vertebral artery, nerve roots and spinal canal, but the benefit of extraction may exceed the risk of complications (8). However, delayed worsening of neurologic complaints may ensue even decades later due to migration or compression from reactive tissue formation and warrant surgical removal (9). Another issue is the fact that the patent might not be able to undergo magnetic resonance imaging because of the fear of projectile migration (10).

This case proves that although gas pistols are not capable of firing real ammunition they can be modified to cause dif- ferent degrees of damage depending on the type and number of projectiles. Although rarely life threatening, damage from modified gas pistols may cause prolonged or life-time discomfort, diminished quality of life and a life long fear of delayed complications.

Ethics Committee Approval: Ethics committee approval was received for this report.

Informed Consent: Written informed consent was obtained from the patient for the publication of this case report and any accompanying images.

Peer-review: Externally peer-reviewed.

Conflict of Interest: No conflict of interest was declared by the author.

Financial Disclosure: The author declared that this report has received no financial support.

\section{REFERENCES}

1. van Deurzen DFP, van As AB, Verleisdonk EJMM. Is routine angiography necessary in patients with a gunshot wound to the neck? A retrospective analysis. Eur J Trauma 2002;28:90-4. [CrossRef]

2. Biffl WL, Moore, EE, Rehce DH, Offner PJ, Franciose RJ, Burch JM. Selective management of penetrating neck trauma based on cervical level of injury. Am J Surg 1997;174:678-82. [CrossRef]

3. Mansour MA, Moore EE, Moore FA, Whitehill TA. Validating the selective management of penetrating neck wounds. Am J Surg 1991;162:517-21. [CrossRef]

4. Vassiliu P, Baker J, Henderson S, Alo K, Velmahos G, Demetriades D. Aerodigestive injuries of the neck. Am Surg 2001;67:75-9.

5. Klyachkin ML, Rohmiller M, Charash WE, Sloan DA, Kearny PA. Penetrating injuries of the neck: Selective management evolving. Am Surg 1997;63:184-9.

6. Gulsen A, Sonmez E, Aydemir F, Caner H, Altinors N. Settled nail injury in the corpus of the seventh cervical vertebra - case report. Neurol Med Chir 2007;47:415-8. [CrossRef]

7. Sasaoka Y, Kamada K, Matumoto M, Ueda Y, Iwasaka T, Hukushima T, et al. Penetrating injury of the head, neck and chest by a nail-gun: A case report. No Shinkei Geka 1995;23:1099-104.

8. Waters RL, Sie IH. Spinal cord injuries from gunshot wounds to the spine. Clin Orthop Relat Res 2003;408:120-5. [CrossRef]

9. Yoshida GM, Garland D, Waters RL. Gunshot wounds to the spine. Orthop Clin North Am 1995;26:109-16.

10. Shaheen F, Singh M, Nazir P. MRI-induced migration of a foreign body into the spinal canal: Are present guidelines safe? Am J Radiol 2008;191:72-3. 